\title{
Comparative case study analysis
}

\section{Claudia Pahl-Wostl, ${ }^{1}$ Xavier Basurto ${ }^{2}$ and Sergio Villamayor-Tomas ${ }^{3}$}

\author{
'INSTITUTE OF GEOGRAPHY, UNIVERSITY OF OSNABRÜCK, OSNABRÜCK, GERMANY \\ ${ }^{2}$ NICHOLAS SCHOOL OF THE ENVIRONMENT, DUKE UNIVERSITY, DURHAM, NORTH CAROLINA, USA \\ ${ }^{3}$ INSTITUTE OF ENVIRONMENTAL SCIENCE AND TECHNOLOGY, AUTONOMOUS UNIVERSITY OF BARCELONA, \\ BARCELONA, SPAIN
}

\section{Key methods discussed in this chapter}

Variable-oriented analysis, archetype analysis (formal concept analysis, qualitative comparative analysis)

\section{Connections to other chapters}

This chapter refers to direct comparisons guided by social-ecological systems frameworks. A prominent SES framework was developed by Elinor Ostrom and contributors of the institutional analysis tradition (Chapter 22). The vulnerability and sustainability livelihood framework (see Chapter 32) has often been used for comparative work. This chapter also connects with data mining and pattern recognition (Chapter 17).

\section{Introduction}

Individual, in-depth case study analyses are quite common in SES research. These analyses provide a deeper understanding of the complexity of social-ecological systems (SES). However, they often deliver case-specific insights and are thus limited in their potential for theory development. Structured case study comparisons are a way forward to leverage theoretical lessons from particular cases and elicit general insights from a population of phenomena that share certain characteristics (Pahl-Wostl 2015).

This chapter focuses on comparative analyses comprising a small or medium number of cases (i.e. 2 to about 30) and qualitative data. It first does so by distinguishing between variable-oriented and case-oriented analyses (Ragin 2004). The aim of variable-oriented analysis is to establish potentially generalisable relationships between features of cases (i.e. variables). These structured comparisons of variables can be guided by SES frameworks (Binder et al. 2013) that facilitate a comparable representation of different case studies. Social-ecological systems frameworks can host comparisons among small numbers of cases and also guide 'qualitative meta-analyses' of a larger number of cases (Rudel 2008). 


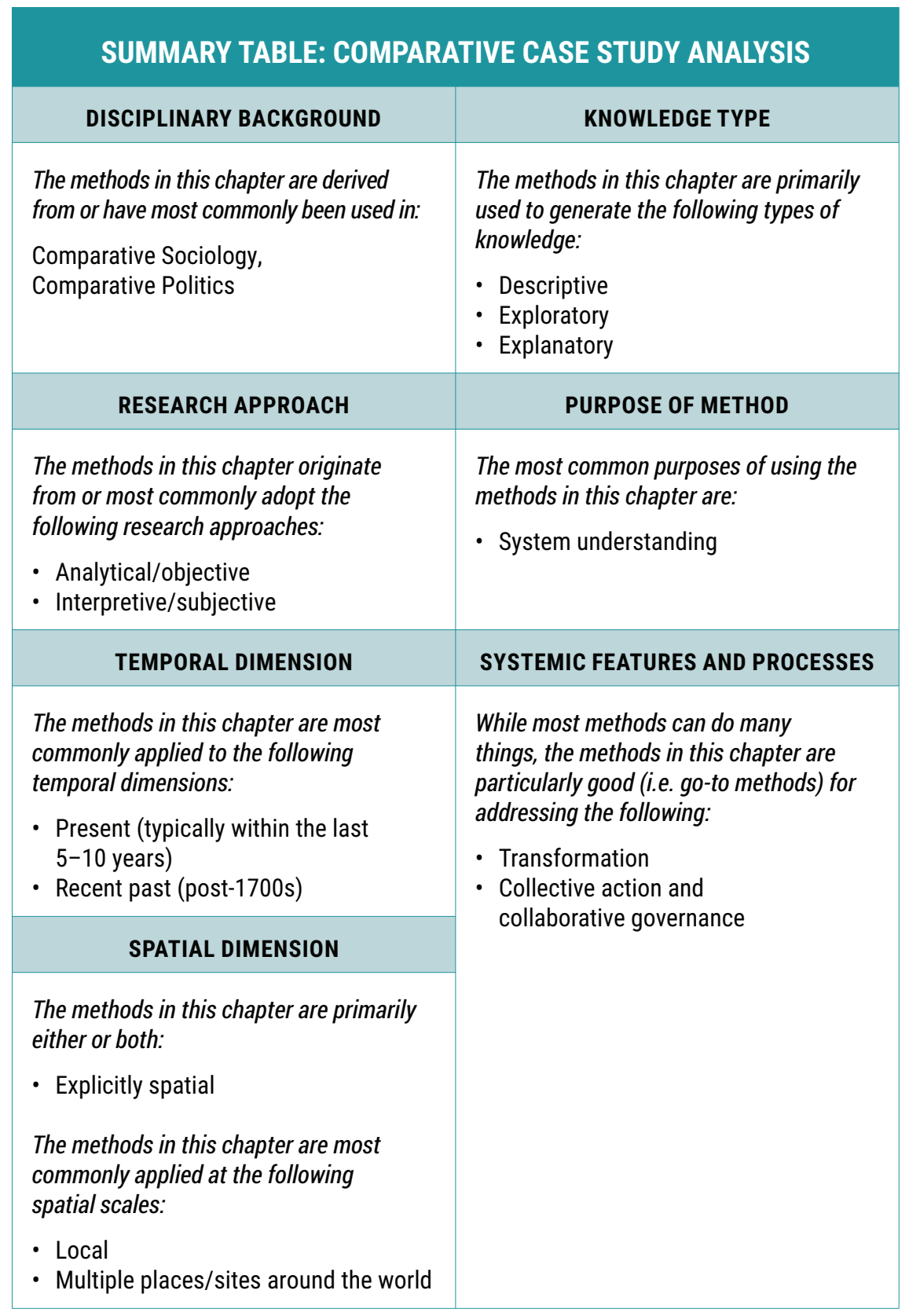


Case-oriented research seeks to understand complex interdependencies rather than simple cause-and-effect relationships. To explain a certain characteristic of an SES (e.g. adaptive capacity), one searches for typical configurations of variables. Here qualitative comparative analysis (QCA) and other qualitative archetype analysis techniques such as formal concept analysis (FCA) have gained increasing popularity in recent years (Ragin and Sonnett 2004; Oberlack et al. 2019). Archetype analysis encompasses a variety of mostly quantitative techniques to identify patterns of complex causation (archetypes of models) and/or state conditions (archetypes of traits).

Qualitative comparative analysis was developed by Charles Ragin, a comparative sociologist, and originates from comparative sociology and comparative politics. Ragin became frustrated by the lack of an analytical technique that dealt with limited diversity (there tends to be less diversity among sets of cases than theoretically possible) and equifinality (i.e. multiple paths leading to the same outcome).

Formal concept analysis (originally Formale Begriffsanalyse in German) is a method used for knowledge representation, information management and data analysis. It was devised in the early 1980s by Rudolf Wille, a German mathematician. He defined 'formal concept' as a unit of analysis comprising a set of objects and their shared attributes (i.e. sets of attributes as they co-occur across groups of cases).

Both qualitative comparative analysis and formal concept analysis allow researchers to group cases and identify configurations of variables as they explain outcomes. Qualitative comparative analysis is a distinct method in the archetype family. It relies on set theory and Boolean algebra, which allow synthesising the configurations to their minimum expression. Formal concept analysis is based on assessing the co-occurrence of variables across cases, which in turn makes it possible to identify subsets of closely related variables within the configurations (Oberlack et al. 2016; Villamayor-Tomas et al. 2020). Conditions that influence the choice of the variable or the case-oriented approaches to comparative analysis range from practical considerations such as stages in a research cycle and the data and methodological skills available to epistemological preferences.

As hinted above, comparative case study research has great potential to build and test middle-range SES theories, i.e. explanations that are generalisable in specific SES contexts. This is accomplished in variable-oriented research by distinguishing between explanatory variables and scope variables (also called 'state variables' or 'parameters'). Explanatory variables feature explanations, whereas scope variables set the empirical boundaries of the explanations (i.e. of generalisations). In case-oriented research the contextualisation of generalisations is less explicit and usually embedded in the description of the phenomenon being studied (e.g. deforestation due to agricultural expansion in small tropical forests) and/or in the scaling of measurements (e.g. small size defined according to the standards for tropical forests).

\section{SES problems and questions}

Variable-oriented comparisons (i.e. both small- $n$ and meta-analyses) have tended to address a wide variety of questions about variable-to-outcome effects. These comparisons can be grouped depending on whether they inquire about influences of social variables on ecological outcomes, the influence of ecological variables on social outcomes, or the reciprocal impact of social and ecological variables (Binder et al. 2013). The questions and social-ecological ambition of comparative analyses are reflected in the SES frameworks used. A fair number of works on ecosystem services have addressed the impact of social variables on ecological variables (i.e. services) in comparative perspective. Typical research questions focus on the effects of different 
land-use strategies on specific services or a variety of services (Schwenk et al. 2012; Ray et al. 2015), and across contexts or scenarios (Fontana et al. 2013; Matthews et al. 2014).

The vulnerability and sustainability livelihood framework (see Chapter 32) has often been used for comparative work addressing the impact of ecological variables on social variables. Comparative studies have mostly taken the form of assessments focusing on social vulnerability to different drivers of change (e.g. climate change and variability, globalisation, migration) and/or in different contexts (e.g. rural areas in a region, cities, coastal zones). There has also been an interest in the influence that different sensitivity variables (e.g. resource dependence, livelihood strategies) and adaptive capacity variables (e.g. education, income, livelihood assets) have on this vulnerability (Turner et al. 2003; Eakin 2005; Simelton et al. 2009). In addition, studies have compared different livelihood strategies in or across local communities and explained those strategies by looking at the influence of biophysical assets (Ferrol-Schulte et al. 2013; Córdova, Hogarth, and Kanninen 2018), among others.

Various comparative works assess reciprocal relations between social and ecological variables. In the water management context, for example, the management and transition framework has inspired studies of environmental change, adaptive management and social learning across basins and countries (Knieper et al. 2010; Kranz, Menniken, and Hinkel 2010). The SES framework was created in response to the comparability issue mentioned in the introduction to this chapter and has since been used to articulate a fair number of studies on the fit between ecological and institutional diversity and cooperation dynamics at local and larger scales (Ostrom 2009; Leslie et al. 2015) (see Chapter 22 for more details).

All the examples above refer mostly to cross-case comparisons, but there are also crosstime comparisons, which can be embedded in cross-case comparisons or just in a single case (Yin 2014). Not many analyses make cross-case comparisons explicit. A number of studies relying on the SES framework have started to do so to assess natural resource management decentralisation processes (Baldwin et al. 2015; Chavez et al. 2019) or the emergence of international environmental regimes (Fleischman et al. 2014; Villamayor-Tomas et al. 2016).

Case-oriented comparisons like those carried out with qualitative comparative analysis and formal concept analysis are particularly well suited to analysing the emergence of phenomena (i.e. how conditions lead to or are associated with outcomes). Neither qualitative comparative analysis nor formal concept analysis looks into processes explicitly, but requires that the researcher thinks and draws hypotheses about them. Rudel (2008), for instance, identified sets of conditions for deforestation around the world and concluded, among other things, that deforestation has shifted from a state-initiated to an enterprise-driven process in the last decades; Basurto's (2013) studies of community-based biodiversity conservation in Costa Rica showed that pathways available for the emergence of collective action for conservation are more limited than those available to maintain it; and Oberlack et al. (2016) identified seven typical processes through which large-scale land acquisitions affect local livelihood vulnerability around the world.

Case-oriented comparisons can also be applied to address integrated system design or institutional fit questions because they make explicit reference to the appropriate combination of different measures to achieve a certain outcome or the conditions under which a certain intervention might achieve a certain outcome (Lam and Ostrom 2010; Roggero 2015; Baggio et al. 2016). Lam and Ostrom (2010), for example, assessed the performance of an innovative governmental programme for irrigation infrastructure improvement in Nepal and found that the effectiveness of the programme was contingent on the existence of strong community-based irrigation associations and local entrepreneurs. Baggio et al. (2016) tested Elinor Ostrom's eight design principles theory for community-based natural resource 
management and concluded that the relevance of some of the principles depended to a great extent on the natural and hard human-made infrastructure available (see also Chapter 22). Roggero (2015) explored the feasibility of coordination among local administrations for the implementation of adaptation plans and found that this coordination can be accomplished if administrators share worldviews and values and have sufficient discretion to make decisions that take one another's interest into account.

Finally, case-based comparisons can support the synthesis of SES features, processes and/ or outcomes into types for descriptive and/or explanatory purposes. Pahl-Wostl and Knieper (2014), for example, used qualitative comparative analysis to explore variation of watergovernance regimes along the two dimensions of decentralisation and coordination. They used the results to confirm the existence of four ideal-typical configurations (i.e. one per combination of features) that are more or less prone to facilitate adaptive capacity (see also Oberlack et al. 2016 for an example).

On a more general note, it is important to note the potential of comparative case studies to develop theory. Although comparative case studies can be used to test theory, the research process usually does not end there. The relative depth of knowledge gained from cases usually provides details that allow researchers to qualify theories (e.g. about the conditions that are fulfilled), which translates into new hypotheses for testing. This is clear in the Basurto (2013) and Baggio et al. (2016) studies mentioned above, for example.

\section{Brief description of key methods}

Variable-oriented comparisons strongly rely on counterfactual analysis, i.e. Mill's comparative methods of most similar and most different systems design (Toshkov 2016). In a most similar systems design, the researcher assesses whether differences between otherwise very similar cases correlate with variation in outcomes. In the most different systems design, the researcher looks for similarities across otherwise very different cases that nevertheless have similar outcomes. Whether in the form of small- $n$ or 'qualitative meta-analyses', the replicability of these direct comparisons can benefit from some tools, including variable books, two-way tables, and rule- and case-based reasoning (Table 20.1).

Table 20.1 Summary of key methods used in comparative case study analysis

\begin{tabular}{|c|c|c|}
\hline Method & Description/tools & References \\
\hline $\begin{array}{l}\text { Direct } \\
\text { comparisons } \\
\text { guided by an } \\
\text { SES framework }\end{array}$ & $\begin{array}{l}\text { Direct comparisons (Mill's comparative methods; } \\
\text { most similar and most different systems design) } \\
\text { require variable books that specify definitions } \\
\text { and operationalisations of attributes, and ensure } \\
\text { the comparability of cases. They can also include } \\
\text { explanations of theoretical importance and } \\
\text { examples. Two-way tables are useful as they } \\
\text { facilitate visualisation and the identification } \\
\text { of differences across cases in terms of the SES } \\
\text { framework variables. When using case-based } \\
\text { reasoning, the relevance of these differences with } \\
\text { regard to whether outcomes are also different is } \\
\text { important. }\end{array}$ & $\begin{array}{l}\text { Key introductory texts } \\
\text { Yin 2014; } \\
\text { Toshkov } 2016 \\
\text { Applications to SES } \\
\text { Basurto, Gelcich, and Ostrom } \\
2013 ; \\
\text { Epstein et al. 2013; } \\
\text { Fleischman et al. } 2014\end{array}$ \\
\hline
\end{tabular}


Method Description/tools References

Rule-based reasoning uses the variable differences

to predict or explain outcomes on the basis of one

or more ecological or social mechanisms (rules)

that link those facts to an outcome (Cox 2011).

\begin{tabular}{|c|c|}
\hline & $\begin{array}{l}\text { Input data for qualitative comparative analysis } \\
\text { are represented in matrix form so that each row } \\
\text { represents a case and each column represents one } \\
\text { of the defined attributes and the outcome. Each } \\
\text { case can therefore be seen as a configuration of } \\
\text { present or absent attributes. } \\
\text { Truth tables synthesise raw data matrices by } \\
\text { collapsing all cases with the same configuration } \\
\text { and then adding a column with the count of } \\
\text { cases per row (i.e. configurations). Then Boolean } \\
\text { algebra is used to synthesise the configurations } \\
\text { into their minimal expression (i.e. solutions). } \\
\text { The impact of attributes on the outcome is assessed } \\
\text { in terms of necessity and sufficiency. The attributes } \\
\text { contained in the solutions are INUS (insufficient } \\
\text { but necessary part of an unnecessary but sufficient } \\
\text { configuration). The explanatory capacity of solutions } \\
\text { can be assessed through measures of consistency } \\
\text { (the percentage of cases with the outcome out } \\
\text { of those matching a solution) and coverage (the } \\
\text { percentage of cases that match a solution out of all } \\
\text { cases with the outcome). }\end{array}$ \\
\hline
\end{tabular}

Formal Formal concept analysis is similar to truth tables

concept in its purpose. As in qualitative comparative

Key introductory texts

Key introductory texts

Ragin 2008;

Rihoux and Ragin 2009;

Schneider and Wagemann

2010

Applications to SES

Sutton and Rudd 2015;

Villamayor-Tomas, Iniesta-

Arandia, and Roggero 2020

analysis analysis, input data are represented by a matrix of cases and attributes (here called a context). A formal concept is defined as the co-occurrence of a set of attributes in a set of cases. Set theory algebra allows one to reason about the nesting of concepts into one another. Less detailed (i.e. Ganter and Wille 2012;

Škopljanac-Mačina and

Blaškovic 2014

Applications to SES

Oberlack et al. 2016;

Oberlack and Eisenack 2018 in number of attributes involved) concepts are supersets of more detailed concepts. This enables the construction of concept lattices.

A concept lattice is a hierarchical relationship of all the concepts of a context in the form of a line diagram. The attributes and groups of cases of each concept are displayed in the nodes. The nodes are in turn linked to one another depending on whether they are part of the same formal concepts or not. 'Higher' attributes in the network are supersets of lower attributes; by the same token, the size of the groups of cases decreases from the 'top down'. 
Case-oriented analyses, in turn, aim to identify recurrent sets of variables (i.e. configurations of attributes) that are associated with outcomes. Qualitative comparative analysis and formal concept analysis both rely on tabular input data (i.e. two-way tables of cases and attributes) and set theory (Table 20.1). Qualitative comparative analysis provides a systematic approach to identifying how the combination of certain conditions leads to an outcome, or how different configurations of conditions lead to the presence of an outcome (resilience, breakdown of a system, cooperation, regime shift, etc.) or its absence. In contrast to regression analyses, qualitative comparative analysis works much better if the scholar has a certain familiarity with cases since one deviant case may lead to the re-evaluation of the conditions associated with the outcome and the potential causal pathways. This iterative process encourages explicit conversation between empirical evidence and theory, and constitutes a particular strength of the method.

In formal concept analysis, a data matrix can contain many concepts. Formal concept analysis allows one to find, visualise and order concepts hierarchically (less detailed concepts encompass more detailed ones). Formal concept analysis has been applied in various fields such as mathematics, medicine, biology, sociology, psychology and economics, mostly for descriptive purposes (Škopljanac-Mačina and Blaškovic 2014). The advantage of formal concept analysis compared to other data representation methods is that it provides information about attribute interdependencies (e.g. dendrograms) as well as a hierarchy of those attributes according to their relevance (e.g. tree diagrams).

Finally, it is worth mentioning process tracing. This is not a technique that allows comparative analysis per se but it can complement both direct comparisons and configurational analyses. Process tracing consists of the identification and questioning of the sequence of events that are supposed to connect cases and outcomes (Collier 2011). In direct comparisons, process tracing is frequently used to confirm that covariance among variables actually reflects causality. In qualitative comparative analysis, process tracing enhances the identification of causal mechanisms and allows addressing the implications that arise from deviant cases (Schneider and Rohlfing 2013). In formal concept analysis, process tracing can be used to examine the relationships that are behind the co-occurrence of variables in explanations (e.g. whether they reflect interaction effects, multiple chains of causality).

\section{Limitations}

Small- $n$ comparative analysis has some limitations that apply to both variable- and caseoriented analyses. An important limitation has to do with the 'too many variables, too few cases', roughly akin to a 'degrees of freedom' issue (which is particularly acute in SES research). A high ratio of variables to cases translates into difficulties to find counterfactuals and make inferences in variable-oriented analyses. In case-oriented analyses, the number of possible configurations increases exponentially with the number of variables. This poses problems to meaningfully synthesise the configurations that are actually observed in the cases at hand. The challenge can be overcome by carefully selecting the variables being studied. In variable-oriented analyses, the selection can benefit from clearly distinguishing scope and explanatory variables, i.e. a good conceptualisation of estate parameters or distant causes, and proximate causes. In case-oriented analyses, it is usually useful to select variables based on expectations about how the interactions of these variables affect outcomes.

Then, there is the issue of data standardisation. Comparisons require the aggregation of deep case study knowledge, which involves missing information and issues of replicability. In variable-oriented analysis, variable books can include some of the missing information as 
well as information to ensure replicability, but only to some extent. In case-oriented analysis, standardisation is more challenging because the scale of variables is set relative to the cases at hand, i.e. they are calibrated. A few works have recently emerged to guide calibration of this nature and set transparency standards (Basurto and Speer 2012).

Neither variable-oriented nor case-oriented analysis methods have been developed to study dynamics. There is thus a lack of guidelines about how to carry out comparisons over time (e.g. how to select time periods and units) and about the difference between over-time comparisons (e.g. comparing well-delimited time periods versus historical analyses, such as characterising a development over time) (Bartolini 1993).

Variable-oriented and case-oriented comparisons also have their own limitations. Variable-oriented comparisons are not particularly suited to assessing interaction effects (at least not as suited as case-oriented comparisons). This is because most similar and most different systems designs are based on isolating the effects of potentially relevant attributes rather than exploring their joint effects. Case-oriented analysis (e.g. qualitative comparative analysis), in turn, has not been generally used to test hypotheses but to build them. Testing hypotheses would require thinking in terms of conditional effects (e.g. variable A has an effect on variable $\mathrm{B}$ depending on the levels of variable $\mathrm{C}$ ), which is a promising but so far rather unexplored inroad (Yamakasi 2003; Hellström 2011). In case-oriented analysis, a related limitation is the fact that it is challenging to make sense of variable configurations because of the general lack of theories that inform interaction effects, particularly if configurations are very large or complex.

\section{Resource implications}

Case comparisons can be resource demanding if data collection requires fieldwork at different field sites. In variable-oriented analysis, case selection can be particularly resource consuming. Both the most similar and the most different systems designs require prior knowledge and a good understanding of which variables will operate as scope or context conditions and which will be more relevant for explanation. Also, the development of variable books in variable-oriented analyses can be time consuming and may require overcoming coordination problems if the data from the cases are collected by different scholars (Cox et al. 2020).

In qualitative comparative analysis, data calibration requires a very good understanding of how the cases at hand vary and the resources needed to revise cases as the analysis unfolds (e.g. to understand deviant cases and/or refine calibrations). Also, both qualitative comparative analysis and formal concept analysis can benefit from the use of software (see fsQCA, R, Concept Explorer) but these need to be learnt. By the same token, training in basic Boolean algebra is essential for a meaningful application of both qualitative comparative analysis and formal concept analysis methods, and the use of software. As with statistics, the methods should not be used as a 'black box', but should be based on a good understanding of the underlying concepts, benefits and trade-offs.

\section{New directions}

Progress in comparative analysis is being made on several fronts. In variable-oriented analysis, an increasing number of case study scholars are becoming aware of the importance of guaranteeing the comparability of their findings and are progressively improving the transparency and interoperability of their data. Platforms like the SES Library at ASU (seslibrary. asu.edu), the Social-Ecological Systems Meta-Analysis Database (SESMAD) at Dartmouth 


\section{Case study 20.1: The influence of water governance on capacity to adapt to climate change}

Failure at multiple levels of governance lies at the core of many water crises. Despite increasing scholarly research on water governance and efforts towards policy reform, the overall situation has not substantially improved and major transformation in water governance is yet to be implemented. Numerous recommendations, often relying on simplistic 'standard' panaceas, have been put forward for water governance reform without testing their appropriateness in diverse socio-economic and environmental contexts. A diagnostic approach and more systematic comparative case study analyses are urgently needed to improve this situation.

Pahl-Wostl et al. (2012) conducted the first comprehensive comparative analysis of complex water governance and management systems in national river basins, compiling insights from 29 basins in developed and developing/emerging countries. The researchers used qualitative approaches and statistical analyses to analyse the interdependencies between the water-governance regime, regime performance, and the environmental and socio-economic context. The example presented here takes this analysis one step further using fsQCA to analyse the importance of polycentricity for performance with respect to climate change adaptation. The analysis built on the hypotheses that ideal types, as depicted in Figure 20.1 (from Pahl-Wostl and Knieper 2014), have a strong explanatory power with respect to understanding the influence of regime configurations on regime performance. The figure depicts the categorisation of governance regimes in a two-dimensional grid of distribution of power and degree of coordination/cooperation. The shaded boxes in the corners denote the ideal-typical configurations.

Case study data were provided by regional experts by means of a questionnaire comprising 81 indicators. For the application of fsQCA, the original score-based dataset had to be converted to fuzzy-set membership values (calibration). These indicators were then aggregated to obtain values for the conditions to be included in the analyses. The conditions included distribution of power (DIS), vertical coordination (VCOR), horizontal coordination (HCOR) and adaptive capacity (ADAP).

College (sesmad.dartmouth.edu) and the Illuminating Hidden Harvests project by Duke University, the Food and Agriculture Organization (FAO) and WorldFish (fao.org/voluntaryguidelines-small-scale-fisheries/ihh/en) are references in that regard. Another promising front in variable-oriented analysis is the systematic study of interactions and processes (Cumming et al. 2020; Villamayor-Tomas et al. 2020). Case study methods are particularly suitable for studying interactions and processes; however, despite recent improvements, these methods tend to be obscured by deeply descriptive and relatively unstructured narratives. Social-ecological systems frameworks (e.g. Ostrom's SES framework) and theory on types of interactions and processes can assist in structuring findings and accumulating knowledge (Villamayor-Tomas et al. 2020).

Case-oriented comparisons in the form of configurational analyses are also blooming. Recent works on syndromes of sustainability (Manuel-Navarrete, Gómez, and Gallopín 2007) and archetypes (Oberlack et al. 2016; Eisenack et al. 2019) are good examples of that. There is 


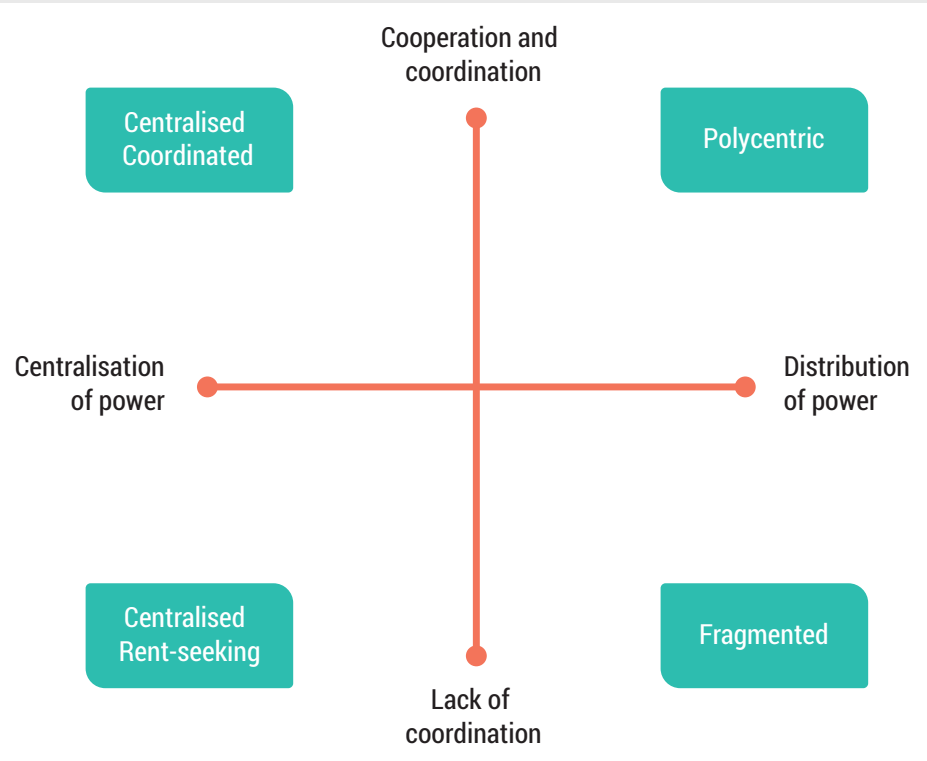

Figure 20.1 Categorisation of governance regimes (Pahl-Wostl and Knieper 2014)

fsQCA was then used to test models for high (ADAP) or low (adap) adaptive capacity, respectively: ADAP $=\mathrm{f}(\mathrm{VCOR}, \mathrm{HCOR}, \mathrm{DIS})$ and adap $=\mathrm{f}(\mathrm{VCOR}, \mathrm{HCOR}$, DIS). The results confirmed the hypotheses regarding the influence of different regime configurations. They showed that a set of factors associated with polycentricity has the highest explanatory power for high performance regarding climate change adaptation. Factors associated with fragmented and centralised regimes can be identified for paths leading to low performance. Furthermore, the analysis identified the effectiveness of formal institutions as an important condition, in particular for paths leading towards low performance.

remarkable potential to develop innovative approaches in mixed-methods research for comparative analysis by combining variable- and case-oriented research, or small- and large- $n$ analyses, for example. Although there have been some advances on this front (Heikkila 2004; Villamayor-Tomas, Iniesta-Arandia, and Roggero 2020), there is still progress to be made, particularly to standardise the methods most suitable to combining, and for specific research purposes.

\section{Key readings}

Basurto, X., S. Gelcich, and E. Ostrom. 2013. 'The Social-Ecological System Framework as a Knowledge Classificatory System for Benthic Small-Scale Fisheries.' Global Environmental Change 23(6): 1366-1380.

Binder, C., J. Hinkel, P.W.G. Bots, and C. Pahl-Wostl. 2013. 'Comparison of Frameworks for Analyzing Social-Ecological Systems.' Ecology and Society 18(4): 26. 
Ragin, C. 2000. Fuzzy-Set Social Science. Chicago: University of Chicago Press.

Schneider C.Q., and C. Wagemann. 2012. Set-theoretic Methods for the Social Sciences. A Guide to Qualitative Comparative Analysis. Cambridge: Cambridge University Press.

Villamayor-Tomas, S., C. Oberlack, G. Epstein, S. Partelow, M. Roggero, E. Kellner, M. Tschopp, and M. Cox. 2020. 'Using Case Study Data to Understand SES Interactions: A Model-centered Meta-analysis of SES Framework Applications.' Current Opinion in Environmental Sustainability.

\section{References}

Baggio, J., A. Barnett, I. Perez-Ibarra, U. Brady, E. Ratajczyk, N. Rollins, C. Rubiños, H. Shin, D. Yu, and R. Aggarwal. 2016. 'Explaining Success and Failure in the Commons: The Configural Nature of Ostrom's Institutional Design Principles.' International Journal of the Commons 10(2): 417-439. doi:10.18352/ijc.634.

Baldwin, E., C. Washington-Ottombre, J. Dell'Angelo, D. Cole, and T. Evans. 2015. 'Polycentric Governance and Irrigation Reform in Kenya.' Governance 29(2): 207-225. doi:10.1111/ gove.12160.

Bartolini, S. 1993. 'On Time and Comparative Research.' Journal of Theoretical Politics 5(2): 131-167. do i: $10.1177 / 0951692893005002001$.

Basurto, X. 2013. 'Linking Multi-level Governance to Local Common-pool Resource Theory Using Fuzzy-set Qualitative Comparative Analysis: Insights from Twenty Years of Biodiversity Conservation in Costa Rica.' Global Environmental Change 23(3): 573-587. doi:10.1016/j. gloenvcha.2013.02.011.

Basurto, X., and E. Ostrom. 2009. 'Beyond the Tragedy of the Commons.' Economia Delle Fonti Di Energia e Dell'Ambiente LII(1): 35-60.

Basurto, X., and J. Speer. 2012. 'Structuring the Calibration of Qualitative Data as Sets for Qualitative Comparative Analysis (QCA).' Field Methods 24(2): 155-174. doi:10.1177/1525822x11433998.

Binder, C.R., J. Hinkel, P.W.G. Bots, and C. Pahl-Wostl. 2013. 'Comparison of Frameworks for Analyzing Social-Ecological Systems.' Ecology and Society 18(4): 26.

Chavez, C., I. Ivania, S. Partelow, R. Madrigal-Ballestero, A. Schlüter, and I. Gutierrez-Montes. 2019. 'Do Responsible Fishing Areas Work? Comparing Collective Action Challenges in Three Small-Scale Fisheries in Costa Rica.' International Journal of the Commons 13(1): 705. doi:10.18352/ ijc. 923 .

Collier, D. 2011. 'Understanding Process Tracing.' Political Science \& Politics 44(4): 823-830. doi:10.1017/ S1049096511001429.

Córdova, R., N. Hogarth, and M. Kanninen. 2018. 'Sustainability of Smallholder Livelihoods in the Ecuadorian Highlands: A Comparison of Agroforestry and Conventional Agriculture Systems in the Indigenous Territory of Kayambi People.' Land 7(2): 45. doi:10.3390/land7020045.

Cox, M. 2011. 'Advancing the Diagnostic Analysis of Environmental Problems.' 2011. International Journal of the Commons 5(2): 346-363. www.thecommonsjournal.org/index.php/ijc/article/view/273.

Cox, M., S. Villamayor-Tomas, N.C. Ban, G. Epstein, L. Evans, F. Fleischman, M. Nenadovic et al. 2020. 'From Concepts to Comparisons: A Resource for Diagnosis and Measurement in Social-Ecological Systems.' Environmental Science \& Policy 107: 211-216. doi:10.1016/j.envsci.2020.02.009.

Cumming, G.S., G. Epstein, J.M. Anderies, C.I. Apetrei, J. Baggio, Ö. Bodin, S. Chawla et al. 2020. 'Advancing Understanding of Natural Resource Governance: A Post-Ostrom Research Agenda.' Current Opinion in Environmental Sustainability 44: 26-34. doi:10.1016/j.cosust.2020.02.005.

Eakin, H. 2005. 'Institutional Change, Climate Risk, and Rural Vulnerability: Cases from Central Mexico.' World Development 33(11): 1923-1938. doi:10.1016/j.worlddev.2005.06.005.

Eisenack, K., S. Villamayor-Tomas, G. Epstein, C. Kimmich, N. Magliocca, D. Manuel-Navarrete, C. Oberlack, M. Roggero, and D. Sietz. 2019. 'Design and Quality Criteria for Archetype Analysis.' Ecology and Society 24(3): 6. doi:10.5751/es-10855-240306.

Epstein, G., J.M. Vogt, S.K. Mincey, M. Cox, and B. Fischer. 2013. 'Missing Ecology: Integrating Ecological Perspectives with the Social-Ecological System Framework.' International Journal of the Commons 7(2): 432-453. doi:10.18352/ijc.371.

Ferrol-Schulte, D., M. Wolff, S. Ferse, and M. Glaser. 2013. 'Sustainable Livelihoods Approach in Tropical Coastal and Marine Social-Ecological Systems: A Review.' Marine Policy 42: 253-258. doi:10.1016/j.marpol.2013.03.007. 
Fleischman, F.D., B. Loken, G.A. Garcia-Lopez, and S. Villamayor-Tomas. 2014. 'Evaluating the Utility of Common-Pool Resource Theory for Understanding Forest Governance and Outcomes in Indonesia between 1965 and 2012.' International Journal of the Commons 8(2): 304-336. www. thecommonsjournal.org/index.php/ijc/article/view/409.

Fontana, V., A. Radtke, V.B. Fedrigotti, U. Tappeiner, E. Tasser, S. Zerbe, and T. Buchholz. 2013. 'Comparing Land-use Alternatives: Using the Ecosystem Services Concept to Define a Multi-Criteria Decision Analysis.' Ecological Economics 93: 128-136. doi:10.1016/j.ecolecon.2013.05.007.

Ganter, B., and R. Wille. 2012. Formal Concept Analysis: Mathematical Foundations. New York: Springer.

Heikkila, T. 2004. 'Institutional Boundaries and Common-pool Resource Management: A Comparative Analysis of Water Management Programs in California.' Journal of Policy Analysis and Management 23(1): 97-117. doi:10.1002/pam.10181.

Hellström, J. 2011. 'Conditional Hypotheses in Comparative Social Science: Mixed-method Approaches to Middle-sized Data Analysis.' Methodological Innovations Online 6(2): 71-102. doi:10.4256/ mio.2010.0036.

Knieper, C., G. Holtz, B. Kastens, and C. Pahl-Wostl. 2010. 'Analysing Water Governance in Heterogeneous Case Studies - Experiences with a Database Approach.' Environmental Science \& Policy 13(7): 592-603.

Kranz, N., T. Menniken, and J. Hinkel. 2010. 'Climate Change Adaptation Strategies in the Mekong and Orange-Senqu Basins: What Determines the State-of-Play?' Environmental Science and Policy 13(7): 648-659. doi:10.1016/j.envsci.2010.09.003.

Lam, W., and E. Ostrom. 2010. 'Analyzing the Dynamic Complexity of Development Interventions: Lessons from an Irrigation Experiment in Nepal.' Policy Sciences 43(1): 1-25. doi:10.1007/ s11077-009-9082-6.

Leslie, H., X. Basurto, M. Nenadovic, L. Sievanen, K.C. Cavanaugh, J.J. Cota-Nieto, B.E. Erisman et al. 2015. 'Operationalizing the Social-Ecological Systems Framework to Assess Sustainability.' Proceedings of the National Academy of Sciences (PNAS) 112(19): 5979-5984. doi/10.1073/ pnas.1414640112.

Manuel-Navarrete, D., J.J. Gómez, and G. Gallopín. 2007. 'Syndromes of Sustainability of Development for Assessing the Vulnerability of Coupled Human-Environmental Systems. The Case of Hydrometeorological Disasters in Central America and the Caribbean.' Global Environmental Change 17(2): 207-217. doi:10.1016/j.gloenvcha.2006.07.002.

Matthews, S.N., L.R. Iverson, M.P. Peters, A.M. Prasad, and S. Subburayalu. 2014. 'Assessing and Comparing Risk to Climate Changes among Forested Locations: Implications for Ecosystem Services.' Landscape Ecology 29(2): 213-228. doi:10.1007/s10980-013-9965-y.

Oberlack, C., and K. Eisenack. 2018. 'Archetypical Barriers to Adapting Water Governance in River Basins to Climate Change.' Journal of Institutional Economics 14(3): 527-555. doi:10.1017/ S1744137417000509.

Oberlack, C., D. Sietz, E.B. Bonanomi, A. de Bremond, J. Dell'Angelo, K. Eisenack, E.C. Ellis et al. 2019. 'Archetype Analysis in Sustainability Research: Meanings, Motivations, and Evidence-Based Policy Making.' Ecology and Society 24(2): 26. doi:10.5751/ES-10747-240226.

Oberlack, C., L. Tejada, P. Messerli, S. Rist, and M. Giger. 2016. 'Sustainable Livelihoods in the Global Land Rush? Archetypes of Livelihood Vulnerability and Sustainability Potentials.' Global Environmental Change 41: 153-171.

Pahl-Wostl, C. 2015. 'A Methodological Framework for Empirical Analyses.' In Water Governance in the Face of Global Change - From Understanding to Transformation by C. Pahl-Wostl, 181-201. New York: Springer.

Pahl-Wostl, C., and C. Knieper. 2014. 'The Capacity of Water Governance to Deal with the Climate Change Adaptation Challenge: Using Fuzzy Set Qualitative Comparative Analysis to Distinguish between Polycentric, Fragmented and Centralized Regimes.' Global Environmental Change 29: 139-154.

Pahl-Wostl, C., L. Lebel, C. Knieper, and E. Nikitina. 2012. 'From Applying Panaceas to Mastering Complexity: Toward Adaptive Water Governance in River Basins.' Environmental Science E Policy 23: 24-34. doi:10.1016/j.envsci.2012.07.014.

Ragin, C. 2004. 'Turning the Tables: How Case-Oriented Research Challenges Variable-oriented Research.' In Rethinking Social Inquiry: Diverse Tools, Shared Standards, edited by H.E. Brady and D. Collier, 123. Oxford: Rowman \& Littlefield. 
Ragin, C. 2008. Redesigning Social Inquiry: Fuzzy Sets and Beyond. Chicago: University of Chicago Press.

Ragin, C., and J. Sonnett. 2004. 'Between Complexity and Parsimony: Limited Diversity, Counterfactual Cases, and Comparative Analysis.' In Vergleichen in Der Politikwissenschaft, edited by S. Kropp and M. Minkenberg, 180-197. Wiesbaden: VS Verlag für Sozialwissenschaften.

Ray, D., S. Bathgate, D. Moseley, P. Taylor, B. Nicoll, S. Pizzirani, and B. Gardiner. 2015. 'Comparing the Provision of Ecosystem Services in Plantation Forests under Alternative Climate Change Adaptation Management Options in Wales.' Regional Environmental Change 15(8): 1501-1513. doi:10.1007/s10113-014-0644-6.

Rihoux, B., and C. Ragin. 2009. Configurational Comparative Methods. Applied Social Research Methods Series. Thousand Oaks: Sage.

Roggero, M. 2015. 'Adapting Institutions: Exploring Climate Adaptation through Institutional Economics and Set Relations.' Ecological Economics 118: 114-122. doi:10.1016/j.ecolecon.2015.07.022.

Rudel, T.K. 2008. 'Meta-Analyses of Case Studies: A Method for Studying Regional and Global Environmental Change.' Global Environmental Change 18(1): 18-25. doi:10.1016/j.gloenvcha.2007.06.001.

Schneider, C.Q., and I. Rohlfing. 2013. 'Combining QCA and Process Tracing in Set-theoretic Multimethod Research.' Sociological Methods E Research 42(4): 559-597. doi:10.1177/0049124113481341.

Schneider, C.Q., and C. Wagemann. 2010. 'Standards of Good Practice in Qualitative Comparative Analysis (QCA) and Fuzzy-sets.' Comparative Sociology 9(3): 397-418. doi:10.1163/1569132 10x12493538729793.

Schwenk, W.S., T.M. Donovan, W.S. Keeton, and J.S. Nunery. 2012. 'Carbon Storage, Timber Production, and Biodiversity: Comparing Ecosystem Services with Multi-criteria Decision Analysis.' Ecological Applications 22(5): 1612-1627. doi:10.1890/11-0864.1.

Simelton, E., E.D.G. Fraser, M. Termansen, P.M. Forster, and A.J. Dougill. 2009. 'Typologies of Crop-drought Vulnerability: An Empirical Analysis of the Socio-economic Factors that Influence the Sensitivity and Resilience to Drought of Three Major Food Crops in China (1961-2001).' Environmental Science \& Policy 12(4): 438-452.

Škopljanac-Mačina, F., and B. Blaškovic. 2014. 'Formal Concept Analysis - Overview and Applications.' In Procedia Engineering 69: 1258-1267. Amsterdam: Elsevier. doi:10.1016/j.proeng.2014.03.117.

Sutton, A.M., and M.A. Rudd. 2015. 'The Effect of Leadership and Other Contextual Conditions on the Ecological and Socio-economic Success of Small-scale Fisheries in Southeast Asia.' Ocean and Coastal Management 114: 102-115. doi:10.1016/j.ocecoaman.2015.06.009.

Toshkov, D. 2016. 'Comparative Designs.' In Research Design in Political Science, edited by D. Toshkov, 258-284. New York: Macmillan.

Turner, B.L., P.A. Matson, J.J. McCarthy, R.W. Corell, L. Christensen, N. Eckley, G.K. Hovelsrud-Broda et al. 2003. 'Illustrating the Coupled Human-Environment System for Vulnerability Analysis: Three Case Studies.' Proceedings of the National Academy of Sciences 100(14). doi:10.1073/ pnas.1231334100.

Villamayor-Tomas, S., M. Avagyan, M. Firlus, G. Helbing, and M. Kabakova. 2016. 'Hydropower vs. Fisheries Conservation: A Test of Institutional Design Principles for Common-pool Resource Management in the Lower Mekong Basin Social-Ecological System.' Ecology and Society 21(1): 3. doi:10.5751/ES-08105-210103.

Villamayor-Tomas, S., I. Iniesta-Arandia, and M. Roggero. 2020. 'Are Generic and Specific Adaptation Institutions Always Relevant? An Archetype Analysis of Drought Adaptation in Spanish Irrigation Systems.' Ecology and Society 25(1): 32. doi:10.5751/ES-11329-250132.

Villamayor-Tomas, S., C. Oberlack, G. Epstein, S. Partelow, M. Roggero, E. Kellner, M. Tschopp, and M. Cox. 2020. 'Using Case Study Data to Understand SES Interactions: A Model-centered Meta-analysis of SES Framework Applications.' Current Opinion in Environmental Sustainability 44(June): 48-57. doi:10.1016/j.cosust.2020.05.002.

Yamakasi, S. 2003. 'Testing Hypotheses with QCA: Application to the Nuclear Phase-out Policy in 9 OECD Countries.' ECPR General Conference. Germany: Marburg.

Yin, R.K. 2014. Case Study Research: Design and Methods. Thousand Oaks: Sage. 